GRASAS Y ACEITES 68 (2)

April-June 2017, e188

ISSN-L: 0017-3495

doi: http://dx.doi.org/10.3989/gya.0818162

\title{
Potentials of enhancing the physicochemical and functional characteristics of Nigella sativa oil by using the screw pressing technique for extraction
}

\author{
S.F. Hamed ${ }^{\mathrm{a}}$, H.A. Shaaban ${ }^{\mathrm{b}}$, A.A. Ramadan ${ }^{\mathrm{c}}$ and A.E. Edris ${ }^{\mathrm{b}, \bigotimes}$ \\ ${ }^{a}$ Fats \& Oils Department, National Research Center, Cairo, Egypt. \\ ${ }^{\mathrm{b}}$ Aroma \& Flavor Chemistry Department, National Research Center, Cairo, Egypt. \\ ${ }^{c}$ Nutrition Department, National Research Center, Cairo, Egypt. \\ ${ }^{\otimes}$ Corresponding author: amr_edris@hotmail.com
}

Submitted: 16 August 2016; Accepted: 25 January 2017

SUMMARY: In the current investigation the crude oil of Nigella sativa was extracted from seeds using hydraulic and screw pressing techniques. Different parameters were evaluated in order to find out the appropriate technique to enhance the physicochemical and functional-related characteristics of the extracted crude oil. Results showed that the acid and peroxide values were significantly lower in the screw pressed oil (SPO) than in the hydraulic pressed oil (HPO). The total phenolic content of the SPO was significantly higher than that of HPO. Evaluation of the oxidative stability using the Rancimat test showed that SPO recorded a much higher oxidative stability index $(40.07 \mathrm{~h})$ than HPO $(0.51 \mathrm{~h})$. The yield of the volatile oil fraction and its contents of thymoquinone isolated from the SPO were higher than that from the HPO. Biological evaluation revealed that the SPO had significantly higher antimicrobial activity than HPO against Listeria monocytogenes and Staphylococcus aureus at $40 \mu \mathrm{L} /$ well.

KEYWORDS: Crude oil; Functionality; Hydraulic pressing; Nigella sativa; Screw pressing

RESUMEN: Mejoras potenciales de las características físico-químicas y funcionales del aceite de Nigella sativa mediante extracción con prensa de tornillo. En la presente investigación se extrajo el aceite crudo de Nigella sativa de las semillas utilizando técnicas hidráulicas y de prensado de tornillo. Se evaluaron diferentes parámetros para conocer la técnica apropiada que potencie las características fisicoquímicas y funcionales del aceite extraído. Los resultados mostraron que los valores de ácido y peróxido fueron significativamente más bajos en el aceite de presión con tornillo (SPO) que en el aceite prensado hidráulico (HPO). El contenido fenólico total del SPO fue significativamente mayor que el de HPO. La evaluación de la estabilidad oxidativa mediante Rancimat demostró que el aceite SPO tiene un índice de estabilidad oxidativa mucho más alto $(40,07 \mathrm{~h})$ que el HPO $(0,51 \mathrm{~h})$. El rendimiento de la fracción volátil y su contenido de timoquinona aislada del aceite SPO fueron superiores a los del HPO. La evaluación biológica reveló que el aceite SPO tenía una actividad antimicrobiana significativamente mayor que el HPO contra Listeria monocitogenes y Staphylococcus aureus a $40 \mu \mathrm{L} /$ pocillo.

PALABRAS CLAVE: Aceite crudo; Funcionalidad; Nigella sativa; Prensado hidráulico; Prensado mediante tornillos

ORCID ID: Hamed SF http://orcid.org/0000-0001-5086-7110, Shaaban HA http://orcid.org/0000-0001-9470-9675, Ramadan AA http://orcid.org/0000-0003-2626-0006, Edris AE http://orcid.org/0000-0001-8213-0770

Citation/Cómo citar este artículo: Hamed SF, Shaaban HA, Ramadan AA, Edris AE. 2017. Potentials of enhancing the physicochemical and functional characteristics of Nigella sativa oil by using the screw pressing technique for extraction. Grasas Aceites 68 (2), e188. http://dx.doi.org/10.3989/gya.0818162

Copyright: (C) 2017 CSIC. This is an open-access article distributed under the terms of the Creative Commons Attribution (CC-by) Spain 3.0 License. 


\section{INTRODUCTION}

Plant oils are among the main sources of supplying humans with energy, fatty acids and oil soluble vitamins. Some of these oils are characterized by additional functionalities and biological activities which makes them suitable for consumption by a wide population sector as a dietary supplement for health promotion or protection against some diseases. Examples of these functional oils which already exist in the supplements' market include flax, pumpkin and Nigella sativa oils. The functionality of these oils (in terms of protective and/or therapeutic activities) has been previously reported (Mason et al., 2015; Biljana et al., 2014; Al-Okbi et al., 2015), respectively.

Functional oils, like many other plant oils, are stored in the seeds; therefore they must be processed to extract their content of oils. Solvent extraction is a large scale method and the industrial method of choice for efficient extraction of seed oil with a yield reaching over $98.0 \%$ (Walkelyn and Wan, 2006). However, the use of organic solvents is considered to be a subject of consideration particularly in producing functional oils due to environmental consideration (solvent vapors) and the potentials of solvent residue in the final product. Due to these considerations, other traditional safe extraction methods are adopted for extracting functional oils from seeds such as the hydraulic and the screw pressing techniques. The hydraulic pressing technique is a traditional batch method which is considered to be suitable for small scale facilities and is based on compression forces that are generated by using mechanical pressure (Willems et al., 2008). Later on, the screw pressing technique was developed to be a continuous extraction technique with more oil recovery, which makes it suitable for medium scale production levels. Screw pressing is characterized by its capacity to extract a greater proportion of oil from the same amount of seeds than the hydraulic pressing technique due to the combination of shear forces (due to friction) and compression forces which operate together on the seeds (Akinoso et al., 2009).

Based on the importance of the hydraulic and screw pressing methods as environmental friendly and safe techniques to extract functional oils for the dietary supplements' market, the authors in the current investigation set out to screen for the most appropriate expression technique in order to enhance the physicochemical and functionalrelated characteristics of the crude oil extracted from the seeds of $N$. sativa. This oil was chosen among other functional oils due to its dietary characteristics as a rich source of essential fatty acids such as linoleic $(54.0-70.0 \%)$ and oleic (15.0-24.0\%), (Tulukcu, 2011). In addition, the oil has protective and therapeutic potentials against some liver diseases as evident from previous work by our group (Al-Okbi et al., 2015; Al-Okbi et al., 2013). N. sativa oil also has a protective effect against oxidative stress (Develi et al., 2014) and other pre-clinical and clinical effects (Gholamnezhad et al., 2016). These functional characteristics make the oil of $N$. sativa an ideal candidate for complementary and continuous investigations aimed at obtaining the most functional benefits of the oil.

In previous reports in the literature the effect of different extraction methods on some physicochemical characteristics of $N$. sativa crude oil was evaluated (Kiralan et al., 2014; Zzaman et al., 2014; Khoddami et al., 2011). However, to our knowledge, there are no trials found so far which examine the effect of hydraulic and screw pressing on the physicochemical characteristics of that crude oil, which will be addressed in the current study. In addition, different parameters related to the functional properties of $N$. sativa oil such as the total phenolic content, thymoquinone content in the volatile oil fraction, the inherent antioxidant capacity of the oil to protect itself against oxidation, and the antimicrobial activity will also be evaluated for oils from both extraction methods. This will lead ultimately to obtaining an overview on the most appropriate pressing technique that leads to enhancing the physicochemical and functional-related properties of $N$. sativa crude oil.

\section{MATERIALS AND METHODS}

\subsection{Materials}

Ten $\mathrm{kg}$ of mature dried seeds of black cumin (Nigella sativa) were purchased from a specialized herbal retail store located in Cairo, Egypt. Gallic acid, Folin-Ciocalteu reagent, 2,2-Diphenyl-1picrylhydrazyl (DPPH), tet-butylhydroquinone (TBHQ) and a series of straight chain alkanes $\left(\mathrm{C}_{8}-\mathrm{C}_{26}\right)$ kit were purchased from Sigma-Aldrich Chemical Co., (St. Louis, USA). All the solvents and other chemicals used were of analytical grade.

\subsection{Extraction of $N$. sativa crude oil}

\subsubsection{Extraction by hydraulic pressing}

$N$. sativa crude oil was extracted from the corresponding seeds by using hydraulic pressing at room temperature (Ustun et al., 1990). The dry seeds were milled into a fine powder, then batches of the powder, $250 \mathrm{~g}$ each, were wrapped in a thick heavy-duty cloth and the oil was extracted using an in-house made hydraulic laboratory scale pressing machine manufactured at the National Research Center, Cairo, Egypt and operated at its maximum pressure (3500 psi) for $1.0 \mathrm{~h}$ at room temperature. The clear extracted crude oil of $N$. sativa was collected 
in dark brown glass bottles equipped with screw caps and stored in the refrigerator until analyzed in less than 1 week. The obtained hydraulic pressed oil is termed (HPO) in this study. The yield percentage of HPO relative to the weight of the seeds was calculated. All extractions were performed in triplicate.

\subsubsection{Extraction by screw pressing}

$N$. sativa crude oil was also extracted from the same batch of seeds by using a commercial scale expeller screw pressing machine located at the same herbal retail store from which the seeds were purchased (Al-Okbi et al., 2015). The seeds were exhaustively screw pressed for two successive cycles and the extracted crude oil of $N$. sativa was filtered and received in dark brown glass bottles equipped with screw caps and stored in the refrigerator until analyzed in less than 1 week. The obtained screw pressed oil is termed (SPO) in this study. The yield percentage of SPO relative to the weight of the seeds was calculated. All extractions were performed in triplicate.

\subsubsection{Extraction by hexane}

$N$. sativa crude oil was also exhaustively extracted from the same batch of seeds by using hot hexane. The ground seeds were placed in extraction thimbles and extracted with n-hexane at $60^{\circ} \mathrm{C}$ for $3 \mathrm{~h}$ using a Soxhlet apparatus. The solvent was died over anhydrous sodium sulfate to absorb any traces of water and then evaporated at $40{ }^{\circ} \mathrm{C}$ under vacuum to obtain the crude oil. The product was weighed and the yield was then calculated based on the weight of the extracted seeds. The yield percentage of the crude oil relative to the weight of the seeds was calculated by dividing the weight of the extracted crude oil by the weight of its corresponding seeds x 100 . All extractions were performed in triplicate.

\subsection{Physicochemical characteristics of the crude oils}

Acid value, peroxide value, saponification value and iodine number were determined according to the American Oil Chemists' Society (AOCS, 1997).

The colors of the HPO and SPO were determined by the Hunter colorimeter (HunterLab, Labscan $\mathrm{XE}$ ) which was used to measure the color using CIE $\mathrm{L} * \mathrm{a} * \mathrm{~b} *$ coordinates (CIELab color scale) according to the American Oil Chemists' Society (AOCS, 1998). The formation of non-enzymatic browning color in the crude oils from both extraction techniques was measured spectrophotometrically using a UV/visible spectrophotometer, (4054-LKB-Biochrom Comp., London, England) at $420 \mathrm{~nm}$ using ethanol as a blank according to a previous method (Birk et al., 1998). All evaluations were performed in triplicate.

\subsection{Total phenolics in the crude oils}

The total phenolic compounds in the extracted HPO and SPO were determined colorimetrically at $725 \mathrm{~nm}$, using the Folin-Ciocalteau reagent (Gutfinger, 1981). Calculations of the total phenolic content in HPO and SPO were done using different concentrations of gallic acid ranging from 0.0 to $450.0 \mathrm{mg} / \mathrm{mL}$. All of the samples were run in triplicate.

\subsection{Oxidative stability of the crude oils}

The oxidative stability of the HPO and SPO was conducted using a Rancimat instrument model 679 Metrohm AG, Switzerland, according to Lutterodt et al., (2010). The accelerated oxidation of the different $N$. sativa crude oils was carried out at 100 C with an air flow rate of $(201 / \mathrm{h})$, using $6 \mathrm{~mL}$ of each crude oil sample. The time period (induction time) required for the crude oil to develop a measurable rancidity which is manifested by a point of inflection on the curve of conductivity against time was determined and called the oxidative stability index (hour). All evaluations were performed in triplicate.

\subsection{Antimicrobial activity of the crude oils}

HPO and SPO were subjected to an antimicrobial evaluation against some food borne pathogenic bacteria. The tested microorganisms were provided from the culture collections of the Microbiological Department National Research Center (NRC) Dokki, Giza, Egypt. These include two strains of Gram-positive bacteria Staphylococcus aureus (ATCC 43300), Listeria monocytogenes (ATCC 35152) and one strain of Gram-negative bacteria Escherichia coli (ATCC 27325).

The antimicrobial evaluation was performed using the agar well diffusion method (Pérez et al., 1990). In detail, $0.1 \mathrm{~mL}$ of the diluted inoculums $\left(10^{7} \mathrm{CFU} / \mathrm{mL}\right)$ of each test organism was spread on tryptone soy agar (TSA) plates. Each of the HPO and SPO was diluted separately with an equal volume of absolute isopropanol $(1,1$, volume ratio) to decrease its viscosity and facilitate diffusion through the agar gel. Then, $40 \mu \mathrm{l}$ and $80 \mu \mathrm{l}$ of each crude oil/isopropanol mixture were transferred into $5 \mathrm{~mm}$ diameter wells that were previously punched into the agar medium. This volume contained $20 \mu \mathrm{L}$ and $40 \mu \mathrm{L}$ of each crude oil/well. The Petri dishes were incubated at $37^{\circ} \mathrm{C}$ for $18 \mathrm{~h}$. The antimicrobial activity was evaluated by measuring the zone of inhibition $(\mathrm{mm})$ corresponding to each tested microorganism. Three replicates for each of the two concentrations were evaluated. 


\subsection{Isolation of the volatile oil fraction from the crude oils}

HPO and SPO were subjected separately to a hydrodistillation process to isolate their volatile oil fractions which were co-extracted with each crude oil during the pressing process. In detail, each crude oil (100g corresponding to $\sim 500 \mathrm{~g}$ seeds) was mixed with distilled water $(1: 7 \mathrm{w} / \mathrm{v})$ in a 51 round bottom flask and distilled for three hours using the Clevenger-type apparatus. The cup that receives the pure volatile oil fraction in the side arm of the apparatus was wrapped with aluminum foil to protect the volatile oil from light. At the end of the distillation each volatile was collected, weighed and its content (yield percent) relative to the weight of its corresponding crude oil was calculated as the mean of three extraction processes \pm S.D.

\subsection{Chemical analysis of the volatile oil fractions using GC and GC-MS}

The volatile oils of $N$. sativa isolated from their corresponding HPO and SPO were first analyzed by gas chromatography (GC). Each volatile oil $(20 \mu \mathrm{L})$ was diluted separately in $1 \mathrm{~mL}$ diethyl ether in a glass vial. Then $2 \mu \mathrm{L}$ of this mixture were injected (at a split ratio 20:1) into a Perkin Elmer XL GC equipped with a FID. A fused silica capillary column HP1-MS $(60 \mathrm{~m} \times$ $0.32 \mathrm{~mm} \times 0.25 \mu \mathrm{m}$ ) was used to separate the different volatile oil components. The oven temperature was programmed from $50{ }^{\circ} \mathrm{C}$ to $230{ }^{\circ} \mathrm{C}$ at a rate of $2{ }^{\circ} \mathrm{C} / \mathrm{min}$. The injector and detector temperatures were $280^{\circ} \mathrm{C}$ and $300{ }^{\circ} \mathrm{C}$ respectively. Helium was used as carrier gas at a flow rate of $1 \mathrm{~mL} / \mathrm{min}$. The volatile oil constituents were semi-quantified as percent of the total peak areas after flame ionization detection. All values were means of three injections from three different extractions \pm SD. The available authentic samples were used to reveal the identity of the volatile oil constituents by matching their retention times with that of the eluted peaks of the volatile oils. The retention index (RI) was also calculated for each peak (Adams 2007) by using a series of straight chain alkanes $\left(\mathrm{C}_{8}-\mathrm{C}_{26}\right)$ kit.

A gas chromatographic-mass spectroscopic analysis (GC-MS) was also conducted in order to reveal and confirm the identity of the components of the different volatile oils. The analysis took place using a Agilent Technologies 7890 A gas chromatograph equipped with a $5975 \mathrm{C}$ quadrupole mass selective detector and the same column used as in the GC analysis. The conditions used for the GC-MS analysis were the same as that previously described in the GC section. The total ion current (m/z 40-400) from the mass spectrometer detector was used to identify the compounds by comparing their mass spectra with that of the in-house mass spectral electronic library.

\subsection{Statistical analysis}

The comparison between all evaluated parameters of HPO and SPO were analyzed using two independent T-tests. The content (yield \%) and the chemical composition of the volatile oil fractions of HPO and SPO were expressed as the means of three measurements \pm S.D. The antimicrobial evaluation of HPO and SPO was analyzed using Mann Whitney's test $(\mathrm{P}<0.05)$. The statistical analysis was carried out using SPSS software version 22.

\section{RESULTS}

\subsection{Effect of pressing technique on the yield and some physicochemical characteristics of the crude oils}

Table 1 shows that there was no significant difference in the yield between hydraulic pressed oil

TABLE 1. Physicochemical parameters of the hydraulic and screw pressed crude oils extracted from the seeds of N. sativa

\begin{tabular}{lccl}
\hline Parameter & Hydraulic pressed oil (HPO) & Screw pressed oil (SPO) & P value \\
\hline Yield of crude oil \% based on seeds & $20.5 \pm 0.28$ & $21.1 \pm 0.14$ & 0.16 \\
Acid value (mg KOH/g oil) & $64.7 \pm 0.14$ & $6.03 \pm 0.02$ & $0.001^{* *}$ \\
Peroxide value (meq. $\mathrm{O}_{2} / \mathrm{kg}$ Oil) & $82.5 \pm 1.27$ & $72.0 \pm 0.28$ & $0.045^{* *}$ \\
Saponification value (mg KOH/g oil) & $188.4 \pm 0.71$ & $189.7 \pm 0.21$ & 0.2 \\
Iodine value (g I / 100 g oil) & $120.6 \pm 0.28$ & $120.7 \pm 0.28$ & 0.76 \\
Original color Index: & $3.79 \pm 0.01$ & $4.35 \pm 0.01$ & $0.002^{* *}$ \\
$\mathrm{~L}^{*}$ & $1.67 \pm 0.02$ & $3.41 \pm 0.01$ & $0.002^{* *}$ \\
$\mathrm{a}^{*}$ & $3.25 \pm 0.01$ & $6.39 \pm 0.01$ & $0.001^{* *}$ \\
$\mathrm{~b}^{*}$ & 0.0 & 0.27 & \\
Color from Non-enzymatic browning: & $38.0 \pm 0.42$ & $67.87 \pm 0.23$ & $0.001^{* *}$ \\
Absorption at 420 nm & $0.51 \pm 0.01^{* *}$ & $40.07 \pm 0.02$ & $0.001^{* *}$ \\
Total phenols* & & & \\
Oxidative stability index (h) & & \\
\hline
\end{tabular}

Results are expressed as mean \pm SD.

$*$ mg gallic acid equivalent $/ \mathrm{kg}$ oil.

$* * \mathrm{p}<0.05$, means within the same row are significantly different. 
(HPO, 20.5\%) and screw pressed oil (SPO, 21.1\%). On the other hand, determination of the crude oil yield after exhaustive seed extraction via the Soxhlet apparatus using hexane as a solvent gave an oil yield of $33.1 \%$. This result means that hydraulic and screw pressing techniques extracted only $62.0 \%$ and $63.4 \%$ of the actual amount of the crude oil present in the seeds, respectively. Previous studies showed that the yield of SPO of N. sativa was 22.5\% (Al-Okbi et al., 2013) and that of an optimized HPO from different seeds of $N$. sativa was $22.0 \%$ (Hadjadj et al., 2014) which are close to our findings.

The Data in Table 1 indicates also that the acid value (AV) of HPO was significantly higher $(64.7 \mathrm{mg}$ $\mathrm{KOH} / \mathrm{g}$ oil) than that of the SPO $(6.03 \mathrm{mg} \mathrm{KOH} / \mathrm{g}$ oil). The AV of SPO was just slightly higher than the standard of Codex Alimentarius Commission (1999) for edible oils which was pre-set at 4.0\% (determined as oleic acid).

The peroxide value (PV) of the HPO was also significantly higher $\left(82.5\right.$ meq. $\mathrm{O}_{2} / \mathrm{kg}$ oil $)$ than the SPO (72.0 meq. $\mathrm{O}_{2} / \mathrm{kg}$ oil). There were no observed significant differences in the saponification and iodine values between the HPO and SPO. These two parameters are the measuring criteria for the molecular weight and the number of double bonds in the triglyceride molecule, respectively.

Regarding the effect of the pressing technique on the color of the crude oil, Table 1 show that there were significant differences in the values of $L^{*}$ (for lightness), $a^{*}$ (for red/green coordinate) and $b^{*}$ (for yellow/blue coordinate) between the HPO and SPO. The oil obtained with the hydraulic pressing (HPO) showed lower values indicating lighter colors than screw pressed oil (SPO), which appears darker. In addition to the natural oil color due to the presence of pigments, there was an increase in optical density of the SPO when measured at $420 \mathrm{~nm}\left(\mathrm{~A}_{420 \mathrm{~nm}}=0.27\right)$ compared to the HPO $\left(\mathrm{A}_{420 \mathrm{~nm}}=0.0\right)$, as shown in Table 1. This indicates the formation of additional color due to the heat induced non-enzymatic browning (Millard reactions) which is initiated by the relatively high extraction temperature of the screw expression process as will be shown later.

Table 1 also indicates that the total phenolic contents of the HPO are significantly lower $38.0 \mathrm{mg}$ gallic acid eq. $/ \mathrm{kg}$ oil) than the SPO $(67.87 \mathrm{mg}$ gallic acid eq./kg oil). In addition, the HPO showed a significantly lower oxidative stability index $(0.51 \mathrm{~h})$ than SPO $(40.07 \mathrm{~h})$, in the accelerated oxidation test (Rancimate). The phenolic content and stability toward oxidation are among the parameters which relate to the inherent antioxidant capacity of the crude oil of $N$. sativa.

It is worth noting that the temperature of the exhausted seeds after the completion of the hydraulic pressing process which took place in an air conditioned room was $25{ }^{\circ} \mathrm{C} \pm 1$. On the other hand, the temperature of the exhausted seeds (flakes) and the oil that came from the machine during the screw pressing process was $50{ }^{\circ} \mathrm{C} \pm 1$ taking in consideration that this process took place in a non-air conditioned and open door herbal retail store in January, where the temperature of the surroundings was $\sim 17{ }^{\circ} \mathrm{C}$. This variation in the extraction temperatures was found to have a significant influence on the physicochemical, chemical and microbiological characteristics of both HPO and SPO as seen in this section and also in the next discussion section.

\subsection{Effect of pressing technique on the content and chemical composition of the volatile oil fractions}

Table 1 shows that the amount of the volatile oil fraction isolated from the SPO was significantly higher $(2.6 \pm 0.03 \mathrm{wt} \%$, based on crude oil) than the one isolated from the HPO $(1.78 \pm 0.04 \mathrm{wt} \%$, based on crude oil). The chemical composition of both volatile oil fractions isolated from HPO and SPO is illustrated in Table 2. From the table it is clear that thymoquinone (TQ) and p-cymene are the most abundant components in both volatile oil fractions. The percentage of TQ in the volatile oil isolated from the SPO was higher $(68.13 \%)$ than from the HPO $(56.29 \%)$. This finding adds to the advantages of SPO due to the well-known functional properties of TQ, as will be shown in the discussion section.

\subsection{Effect of extraction technique on the antimicrobial activity of the crude oils}

Table 3 shows that the SPO at its low dose (20 $\mu \mathrm{L} /$ well) and high dose $(40 \mu \mathrm{L} /$ well $)$ inhibited the growth of $E$. coli, while the HPO was totally ineffective against this microorganism at both doses. Meanwhile, SPO showed significantly higher antimicrobial activity than HPO against Listeria monocytogenes at both doses. In case of Staphylococcus aureus there was no significant difference in the antimicrobial activity of both oils at the low dose (20 $\mu \mathrm{L} /$ well), while at the higher dose $(40 \mu \mathrm{L} /$ well $)$ SPO showed significantly higher antimicrobial activity than HPO. From Table 3 it is also evident that both HPO and SPO are highly effective (to different degrees) against Staphylococcus aureus compared with E. coli and Listeria monocytogenes at all doses as evident from the higher inhibition zones shown for S. aureus.

\section{DISCUSSION}

In the current investigation the crude oil of $N$. sativa seeds was extracted using hydraulic and screw pressing techniques which are the traditional methods to obtain solvent-free functional oils. Theoretically, screw pressing should give a higher crude oil yield than hydraulic pressing due to the 
TABLE 2. Chemical composition of the volatile oil fractions isolated from hydraulic and screw pressed crude oils of N. sativa

\begin{tabular}{lccc}
\hline & IR & \multicolumn{2}{c}{ Relative area \% } \\
\cline { 2 - 4 } Chemical composition & & $\begin{array}{c}\text { Volatile oil isolated from } \\
\text { hydraulic pressed oil (HPO) }\end{array}$ & $\begin{array}{c}\text { Volatile oil isolated from screw } \\
\text { pressed oil (SPO) }\end{array}$ \\
\hline$\alpha$-thujene & 924 & $3.66 \pm 0.17$ & $0.73 \pm 0.04$ \\
$\alpha$-pinene & 930 & $0.79 \pm 0.01$ & $0.14 \pm 0.02$ \\
sabinene & 965 & $0.62 \pm 0.01$ & $0.21 \pm 0.02$ \\
$\beta$-pinene & 969 & $1.35 \pm 0.07$ & $0.49 \pm 0.03$ \\
$\alpha$-terpinene & 1009 & 0.00 & $0.06 \pm 0.01$ \\
p-cymene & $\mathbf{1 0 1 3}$ & $\mathbf{2 6 . 2} \pm \mathbf{0 . 1 3}$ & $\mathbf{2 0 . 1 1} \pm \mathbf{0 . 3 6}$ \\
limonene & 1021 & $1.26 \pm 0.02$ & $0.79 \pm 0.04$ \\
$\gamma$-terpinene & 1049 & $0.03 \pm 0.0$ & 0.00 \\
cis-4-methoxythujane & 1088 & $0.63 \pm 0.0$ & $0.53 \pm 0.05$ \\
trans-4-methoxythujane & 1110 & $3.82 \pm 0.01$ & $3.75 \pm 0.20$ \\
terpinene-4-ol & 1162 & $0.55 \pm 0.0$ & $0.72 \pm 0.04$ \\
thymoquinone & $\mathbf{1 2 2 3}$ & $\mathbf{5 6 . 2 9 \pm 0 . 2 1}$ & $\mathbf{6 8 . 1 3} \pm \mathbf{0 . 8 6}$ \\
bornyl acetate & 1269 & $0.11 \pm 0.0$ & $0.1 \pm 0.01$ \\
Carvacrol & 1278 & $0.9 \pm 0.01$ & $0.76 \pm 0.35$ \\
$\alpha$-Longipinene & 1354 & $0.32 \pm 0.01$ & $0.38 \pm 0.02$ \\
Longifolene & 1408 & $1.25 \pm 0.01$ & $1.71 \pm 0.02$ \\
\hline
\end{tabular}

Peak areas are means of three injections \pm SD.

TABLE 3. Antimicrobial activity of hydraulic and screw pressed crude oils extracted from the seeds of N. sativa

\begin{tabular}{|c|c|c|c|c|c|c|}
\hline \multirow[b]{4}{*}{ Pathogenic bacteria } & \multicolumn{6}{|c|}{ Amount of $N$. sativa crude oil } \\
\hline & \multicolumn{3}{|c|}{$20 \mu \mathrm{L} /$ well } & \multicolumn{3}{|c|}{$40 \mu \mathrm{L} /$ well } \\
\hline & \multicolumn{6}{|c|}{ Inhibition zone (mm) } \\
\hline & HPO & SPO & p value & HPO & SPO & p value \\
\hline E. coli & 0.0 & $11.67 \pm 0.58$ & - & 0.0 & $13.67 \pm 0.58$ & - \\
\hline Listeria monocytogenes & $7 \pm 0.0$ & $11 \pm 1.73$ & $0.034 *$ & $11 \pm 0.0$ & $13.67 \pm 0.58$ & $0.034 *$ \\
\hline Staphylococcus aureus & $28.33 \pm 3.51$ & $26 \pm 1$ & 0.38 & $34.33 \pm 2.08$ & $40 \pm 2$ & $0.05^{*}$ \\
\hline Isopropanol (control) & -ve & -ve & - & -ve & -ve & - \\
\hline
\end{tabular}

Results are expressed as mean \pm SD.

$* \mathrm{p}<0.05$, means within the same row are significantly different.

combination of the shear forces beside the compression forces which work together on the seeds, as previously indicated in the introduction section. However, from Table 1 it is clear that there was no significant difference between the yield of HPO and SPO. That can be justified by the fact that the extraction efficiency of the screw pressing machine may decrease over time due to continues use, which consequently decreases the oil yield, making it comparable to that obtained by HPO.

The physical and chemical attributes of oils can directly affect their shelf life and functionality. Parameters like the acid value (AV), peroxide value (PV), oxidation stability and the color are basic criteria which are used to evaluate the quality characteristics of the oils and the suitability of the extraction method. Table 1 shows that there is a difference in AV between HPO and SPO. That difference could be due to the de-activation (de-naturation) of lipase enzyme which is naturally present in the seeds, under the effect of the relatively high temperature $\left(\sim 50{ }^{\circ} \mathrm{C}\right)$ during the screw pressing extraction (see results section). As a result, the lipolysis of triglyceride under the effect of lipase during extraction could be reduced in SPO. Consequently less free fatty acids are liberated from the SPO, which justify its lower AV. On the contrary, such lipase deactivation is not likely to happen in the HPO in which the extraction temperature does not exceed that of the room temperature $\left(\sim 25^{\circ} \mathrm{C}\right)$. This leads to greater potential for lipolytic activity during extraction which in turn can increase the AV. This justification came in accordance with a previous study (Dandik and Aksoy, 1992) although the authors estimated 
the effect of temperature on lipase activity by subjecting the seeds to different temperatures in an oven instead of proceeding under real mechanical pressing conditions which generate inherent heat, as the case in our investigation.

When oils oxidize they produce a series of breakdown products at different stages starting with primary oxidation products like peroxides, which can be determined experimentally as peroxide value (PV). From the results in Table 1 it is evident that the peroxide value (PV) of the HPO is significantly higher (82.5 meq. $\mathrm{O}_{2} / \mathrm{kg}$ oil) than SPO (72.0 meq. $\mathrm{O}_{2} / \mathrm{kg}$ oil). That gave a preliminary indication that screw pressing could reduce the formation of peroxides probably by extracting some antioxidant agent(s) from the seeds of $N$. sativa to a greater extent than hydraulic pressing. Some of these agents could be the phenolic compounds which are known to possess antioxidant activity (Rice-Evans et al., 1997). This postulation was supported and verified by the determination of the total phenolic content of both oils which revealed that SPO contains higher total phenolic contents (67.87 mg gallic acid/kg oil) than HPO (38.0 mg gallic acid/kg oil). That is due to the generated heat during screw pressing which led to enhanced recovery of biologically active compounds like phenolics.

Beside the contribution of total phenolic content, the increase in the PV of HPO (82.8) can also be considered as a consequence of its high AV (64.7 mg KOH/g oil, Table 1). The acid value increase is due to the increase in free fatty acids (FFA) liberated from the triglyceride by the action of lipase. These FFA are known to have a pro-oxidant action which is exerted by the carboxylic molecular group that accelerates the rate of decomposition of hydroperoxides leading to an elevation of the PV (Miyashita and Takagi, 1986). This process can also take place in the SPO but to a lesser extent than HPO due to its lower acid value (6.03 $\mathrm{mg} \mathrm{KOH} / \mathrm{g}$ oil), as shown in Table 1 .

A comparison between our result from the PV evaluation and other investigations reveals the presence of a crude oil of $N$. sativa with a much lower $\mathrm{PV}$ value (4.3-5.6 meq. $\mathrm{O}_{2} / \mathrm{kg}$ oil), (Cheikh-Rouhou et al., 2007). On the contrary, much higher PV values (204.5-342.3 meq. O2/kg oil) were also reported (Zzaman et al., 2014). Variations in PV values could be related to the difference in the extraction method, source and nature of the seeds, difference in the period of seed storage before processing and also variation in the storage conditions, particularly humidity and temperature.

The stability of oils against oxidation during shelf life is one of the most important quality criteria. It can be evaluated in a rapid manner to save long storage time by using the accelerated oxidation test under high temperature which is known as the Rancimate test (Lutterodt et al., 2010). Table 1 shows that SPO persisted much longer and possessed a higher oxidative stability index $(40.07 \mathrm{~h})$ in the Rancimate test than HPO $(0.51 \mathrm{~h})$. This clearly indicates that the SPO had more inherent antioxidant agent(s) which enabled the oil to persist for longer against oxidation than HPO. The higher total phenolic contents of SPO (67.87 mg gallic acid/kg oil) could be one of the major reasons for its stability against oxidation, as indicated before. Previous studies have revealed the direct correlation between the total phenolic content and oxidative stability of $N$. sativa crude oil. For instance, an oxidative stability index of $55.0 \mathrm{~h}$ in the Rancimat test was reported for a crude oil of $N$. sativa that had total phenolic content $309.0 \mathrm{mg}$ gallic acid/kg oil (Cheikh-Rouhou et al., 2007).

Beside the crucial role of the total phenolics in suppressing the oxidation process and prolonging shelf life, the presence of a minor volatile oil fraction in the crude oil of $N$. sativa can also contribute to its oxidative stability. In the current investigation, that volatile oil fraction was separated from the crude oils of both SPO and HPO using hydrodistillation. A quantitative evaluation revealed that SPO contained significantly higher volatile oil content $(2.6 \mathrm{wt} \%$ based on crude oil) than HPO (1.78 wt $\%$ based on crude oil). A study by Edris, (2011) revealed a variation in the oxidative stability index (26.9 h versus $2.58 \mathrm{~h}$ ) of two different crude oils of $N$. sativa as a function of their volatile oil content ( $1.8 \mathrm{wt} \%$ versus $0.1 \mathrm{wt} \%$ ), respectively. The importance of the volatile oil fraction in the suppression of oxidation of its parent crude oil is attributed to its content of thymoquinone (TQ). This volatile compound is known to possess a potent antioxidant activity (Ismail et al., 2009). The results in Table 2 indicate that the thymoquinone (TQ) percentage of the volatile oil isolated from the SPO was higher $(68.13 \%)$ than that isolated from the HPO $(56.29 \%)$. This is due to the higher volatile oil content in SPO $(2.6 \%)$, as previously indicated. In addition, TQ in its native state is composed of solid crystals with a melting point of $45-47^{\circ} \mathrm{C}$. So the heat generated during the extraction of SPO $\left(\sim 50{ }^{\circ} \mathrm{C}\right)$ can cause melting of the crystals of this compound and facilitate its co-extraction with the crude oil leading to a higher percentage in the volatile fraction of SPO. One should bear in mind that TQ is the compound that gives the volatile oil and consequently its parent crude oil their functionality due to the pharmaceutical and therapeutic properties of this compound (Gülşen et al., 2016; Darakhshan et al., 2015; Schneider-Stock et al., 2014). From the above mentioned, it could be presumed that the high yield of the volatile oil fraction $(2.6 \%)$ along with its high content of TQ $(68.13 \%)$ of the SPO can be considered contributing factors that justify the high oxidative stability and relatively lower PV of that oil, as mentioned in the previous sections.

Table (2) also shows that p-cymene is the second most abundant constituent in the volatile oil fractions of SPO $(20.11 \%)$ and HPO $(26.2 \%)$. However, this 
compound does not contribute to the oxidative stability of its parent crude oils as TQ does, due to the lack of proton donating groups in its chemical structure.

Color is one of the attributes of seed oils which originates from the presence of some pigments in the seeds or the plant part from which the oil is extracted. In case of $N$. sativa, the epidermis layer of the seeds' testa is composed of compact polygonal cells which are rich in dark-colored pigments. These pigments mainly include chlorophyll and carotenoids at different ratios which can reach up to 2.0 $\mathrm{mg} / \mathrm{kg}$ each, depending on the seeds (Zzaman et al., 2014). These pigments, especially chlorophylls and carotenoids, are co-extracted with the oil upon the expression of the seeds, giving the oil it characteristic color. In the current investigation, the authors studied the effect of expression techniques on the color characteristics of the obtained crude oil of $N$. sativa. HPO had lighter colors than screw pressed oil (SPO), which appear darker. This result is a common consequence of the high extracting ability of the screw pressing process.

The antimicrobial activity of the crude oil of $N$. sativa was previously addressed by different investigators particularly against multi-drug resistant bacteria (Salman et al., 2008). However the effect of pressing technique on the extent of this activity is yet to be investigated. Therefore in the current investigation the antimicrobial activities of HPO and SPO of $N$. sativa against different pathogenic microorganisms were subjected to evaluation at two different doses, $20 \mu \mathrm{l} /$ well and $40 \mu \mathrm{l} /$ well. Table 3 shows that there is a differential behavior of antimicrobial activity between HPO and SPO. This behavior can be rationalized based on the difference in the content of the volatile oil fraction and TQ percentage in each of the two crude oils. In more detail, at 20 $\mu \mathrm{l} /$ well, HPO contained $0.299 \mathrm{mg}$ of the volatile oil fraction while SPO contained $0.437 \mathrm{mg}$, (based on the content of each volatile oil in both crude oils, see results section). Meanwhile, at the higher concentration $(40 \mu \mathrm{l} /$ well $)$ HPO contained $0.598 \mathrm{mg}$ while SPO contained $0.874 \mathrm{mg}$ of that volatile fraction. This volatile fraction and its major constituent TQ are the main cause of the antimicrobial activity of $N$. sativa crude oil (Chaieb et al., 2011), and both of them were higher in SPO. One should also consider the potential participation of the other non volatile constituents like the phenolic compounds to the overall antimicrobial activity of the crude oils. These compounds were higher in the SPO than in HPO, as previously indicated (Table 1). Based on the above mentioned, it worth indicating that the high antimicrobial activity of SPO, which was illustrated in Table 3, can add to the functionality of that oil. Therefore, the consumption of SPO as a daily supplement may potentially protect against illness caused by pathogenic bacteria which contaminate minimally processed or unprocessed food products.

\section{CONCLUSIONS}

In conclusion, the screw pressing extraction of $N$. sativa seeds can produce a crude oil with better characteristics than hydraulic pressing under the conditions of the current investigation. This result could be of interest to the complementary supplements and nutraceutical field to take into consideration for maximizing the functional properties and general quality of $N$. sativa crude oil.

\section{Conflict of interest}

The authors declare that there is no conflict of interest.

\section{REFERENCES}

Adams, R. P. (2007). Identification of essential oil components by gas chromatography/quadrupole mass spectroscopy (4th ed.). Illinois: Allured Publishing Corporation.

Akinoso R, Raji A, Igbeka J. 2009. Effects of compressive stress, feeding rate and speed of rotation on palm kernel oil yield. J. Food Eng. 93, 427-430. http://dx.doi.org/10.1016/j. jfoodeng.2009.02.010

Al-Okbi S, Mohamed D, Hamed T, Edris A. 2015. Evaluation of the therapeutic effect of Nigella sativa crude oil and its combination with omega-3 fatty acids-rich oils in a modified hepatorenal syndrome model in rats. Grasas Aceites 66, e103. https://doi.org/10.3989/gya.0245151

Al-Okbi S, Mohamed D, Hamed T, Edris A. 2013. Potential protective effect of Nigella sativa crude oils towards fatty liver in rats. Eur. J. Lipid Sci. Tech. 115, 774-782. http://dx.doi. org/10.1002/ejlt.201200256

AOCS Official Methods of Analysis. Methods Cd 8-53; Cd 3d-63; Cd 3-25; Cd 3d-63; AOCS: Champaign, Illinois, USA, 1997.

AOCS Official Methods of Analysis. Method Cc 13b-45; AOCS: Champaign, Illinois, USA, 1998.

Biljana R, Etelka D, Miroslav N, Vele T, Zorica B. 2014. The most important bioactive components of cold pressed oil from different pumpkin (Cucurbita pepo L.) seeds. LWTFood Sci. Tech. 55, 521-527. http://dx.doi.org/10.1016/j. lwt.2013.10.019

Birk E, Mannheim C, Saguy I. 1998. A rapid method to monitor quality of apple juice during thermal processing. Lebensm. Wiss. Technol. 31, 612-616. http://dx.doi.org/10.1006/ fstl.1998.0385

Chaieb K, Kouidhi B, Jrah H, Mahdouani K, Bakhrouf A. 2011. Antibacterial activity of thymoquinone; an active principle of $N$. sativa and its potency to prevent bacterial biofilm formation. BMC Complemen. Alt. Med. 11, 29-34. http://dx.doi.org/10.1186/1472-6882-11-29

Cheikh-Rouhou S, Besbes S, Hentati B, Blecker C, Deroanne C, Attia H. 2007. Nigella sativa L.: Chemical composition and physicochemical characteristics of lipid fraction. Food Chem. 101, 673-681. http://dx.doi.org/10.1016/j. foodchem.2006.02.022

Codex Alimentarius, 1999. Guidelines for the production, processing, labelling and marketing of organically produced foods.

Dandik L, Aksoy H. 1992. The kinetics of hydrolysis of Nigella Sativa (Black Cumin) seed oil catalyzed by native lipase in ground seed. J. Am. Oil Chem. Soc. 69, 1239-1241. http:// dx.doi.org/10.1007/BF02637689

Darakhshan S, Pour A, Colagar A, Sisakhtnezhad S. 2015. Thymoquinone and its therapeutic potentials. Pharm. Res. 95-96, 138-158. http://dx.doi.org/10.1016/j. phrs.2015.03.011

Develi S, Evran B, Kalaz E, Koçak-Toker N, Erata G. 2014. Protective effect of Nigella sativa oil against binge 
ethanol- induced oxidative stress and liver injury in rats. Chin. J. Nat. Med. 12, 495-499. http://dx.doi.org/10.1016/ S1875-5364(14)60077-7

Edris A. 2011. The chemical composition and the content of volatile oil: potential factors that can contribute to the oxidative stability of Nigella sativa L. crude oil. J. Diet. Suppl. 8, 34 42. http://dx.doi.org/10.3109/19390211.2010.547242

Gholamnezhad Z, Havakhah S, Boskabady M. 2016. Preclinical and clinical effects of Nigella sativa and its constituent, thymoquinone: A review. J. Ethnopharmacol. 190, 372-386. http://dx.doi.org/10.1016/j.jep.2016.06.061

Gülșen I, Ak H, Cölçimen N, Alp H, Akyol M, Demir I, Atalay T, Balahroğlu R, Rağbetli M. 2016. Neuroprotective effects of thymoquinone on the hippocampus in a rat model of traumatic brain injury. World Neurosurg. 86, 243-249. http://dx.doi.org/10.1016/j.wneu.2015.09.052

Gutfinger T. 1981. Polyphenols in olive oils. J. Am. Oil Chem. Soc. 58, 966-968. http://dx.doi.org/10.1007/BF02659771

Hadjadj N, Acheheb H, Aitchaouche F, Belhachat D, Ferradji A. 2014. Optimization of oil extraction from Nigella sativa seeds by pressing using response surface methodology. Am. J. Food Tech. 9, 136-143. http://dx.doi.org/10.3923/ ajft.2014.136.143

Ismail M, Al-naqeep G, Chan W. 2009. Nigella sativa thymoquinone-rich fraction greatly improves plasma antioxidant capacity and expression of antioxidant genes in hypercholesterolemic rats. Free Rad. Biol. Med. 48, 664-672. http:// dx.doi.org/10.1016/j.freeradbiomed.2009.12.002

Khoddami A, Ghazali H, Yassoralipour A, Ramakrishnan Y, Ganjloo A. 2011. Physicochemical characteristics of Nigella seed (Nigella sativa L.) oil as affected by different extraction methods. J. Am. Oil Chem. Soc. 88, 533-540. http://dx.doi.org/10.1007/s11746-010-1687-6

Kiralan M, Özkanb G, Bayrakc A, Ramadan F. 2014. Physicochemical properties and stability of black cumin (Nigella sativa) seed oil as affected by different extraction methods. Ind. Crops Prod. 57, 52-58. http://dx.doi. org/10.1016/j.indcrop.2014.03.026

Lutterodt H, Luther M, Slavin M, Yin J, Parry J, Gao M, Yu L. 2010. Fatty acid profile, thymoquinone content, oxidative stability, and antioxidant properties of cold-pressed black cumin seed oils. LWT - Food Sci. Tech. 43, 1409-1413. http://dx.doi.org/10.1016/j.lwt.2010.04.009

Mason J, Fu M, Chen J, Thompson L. 2015. Flaxseed oil enhances the effectiveness of trastuzumab in reducing the growth of HER2-overexpressing human breast tumors (BT-474). J. Nutr. Biochem. 26, 16-23. http://dx.doi. org/10.1016/j.jnutbio.2014.08.001

Miyashita K, Takagi T. 1986. Study on the oxidative rate and prooxidant activity of free fatty acids. J. Am. Oil Chem. Soc. 63, 1380-1384. http://dx.doi.org/10.1007/BF02679607

Perez C, Pauli M, Bazerque P. 1990. An antibiotic assay by the well agar diffusion method. Acta Bio. Med. Exp. 15, $113-115$.

Rice-Evans C, Miller N, Paganga G. 1997. Antioxidant properties of phenolic compounds. Trend Plant Sci. 2, 152-159. http://dx.doi.org/10.1016/S1360-1385(97)01018-2

Salman M, Khan R, Shukla I. 2008. Antimicrobial activity of Nigella sativa Linn. seed oil against multi-drug resistant bacteria from clinical isolates. Nat. Prod. Rad. 7, 10-14.

Schneider-Stock R, Fakhoury H, Zaki M, El-Baba O, GaliMuhtasib H. 2014. Thymoquinone: fifty years of success in the battle against cancer models. Drug Discov. Today 19 , 18-30. http://dx.doi.org/10.1016/j.drudis.2013.08.021

Tulukcu F. 2011. A comparative study on fatty acid composition of black cumin obtained from different regions of Turkey, Iran and Syria. Afric. J. Agric. Res. 6, 892-895.

Ustun G, Kent L, Cekin N, Civelekoglu H. 1990. Investigation of the technological properties of N. sativa (black cumin) seed oil. Am. Oil Chem. Soc. 67, 958-960. https://doi. org/10.1007/BF02541857

Walkelyn J, Wan J. 2006. Solvent extraction to obtain edible oil products, in Akoh C (Ed.), Handbook of Functional Lipids. Boca Raton, CRC Press, pp. 89-131.

Willems P, Kuipers N, De Haan A. 2008. Hydraulic pressing of oilseeds: Experimental determination and modeling of yield and pressing rates. J. Food Eng. 89, 8-16. http:// dx.doi.org/10.1016/j.jfoodeng.2008.03.023

Zzaman W, Silvia D, Abdullah W, Yang A. 2014. Physicochemical and quality characteristics of cold and hot press of Nigella sativa L seed oil using screw press. J. Appl. Sci. Res. 10, $36-45$. 